\title{
Involvement of HAND1 and CBS in maintenance of cardiac micro-architecture following obesity-induced heart failure
}

\author{
Xiandong Sun ${ }^{1}$, Jian Cao ${ }^{2}$, Haiming Tong ${ }^{3}$, Xizhe Zhang ${ }^{4}$, Yi Sun ${ }^{4}$, Zhimin Wei ${ }^{1}$, \\ Ronghai $\operatorname{Man}^{1 *}$ \\ ${ }^{1}$ Department of Cardiology, ${ }^{2}$ Department of Orthopedics, ${ }^{3}$ Department of Emergency, ${ }^{4}$ Department of Anesthesiology, Chifeng \\ Municipal Hospital, Chifeng, Inner Mongolia, 024000, China
}

*For correspondence: Email: RClelandechen@yahoo.com; Tel: 0086-4768352060

\begin{abstract}
Purpose: To study the role of heart and neural crest derivatives expressed 1 (HAND1) and cystathionine-beta-synthase (CBS) in the maintenance of cardiac architecture following high fat dietinduced obesity.

Methods: Mouse models of initial and critical heart disease were established by continuous feeding of high fat diet for 7 and 12 months, respectively. The expression of HAND1 and CBS were assayed using immunohistochemistry and Western blotting.

Results: Obesity led to mild and severe forms of heart disease which were confirmed through histological imaging. Initial obesity resulted in cardiac tissue remodeling along with initial degeneration, while critical obesity resulted in tissue hardening. The expression of HAND1 was upregulated 4.3 folds in the mild form of cardiac failure, relative to marginal expression pattern of HAND1 in control tissue. However, as the disease progressed, the expression of HAND1 was limited in serve form of cardiac failure. Moreover, the expression of cystathionine beta-synthase (CBS) was upregulated 3.7-fold in the initial form of heart failure, but was subsequently reduced in serve form of heart disease.

Conclusion: These results reveal that in high fat diet-induced cardiac stress, the over-expressions of HAND1 and CBS at the initial stages induce extensive alterations in cardiac architecture.
\end{abstract}

Keywords: Obesity, High-fat diet, Heart and Neural Crest Derivatives Expressed 1, Cystathionine-betasynthase, Cardiac re-modeling

This is an Open Access article that uses a fund-ing model which does not charge readers or their institutions for access and distributed under the terms of the Creative Commons Attribution License (http://creativecommons.org/licenses/by/4.0) and the Budapest Open Access Initiative (http://www.budapestopenaccessinitiative.org/read), which permit unrestricted use, distribution, and reproduction in any medium, provided the original work is properly credited.

Tropical Journal of Pharmaceutical Research is indexed by Science Citation Index (SciSearch), Scopus, International Pharmaceutical Abstract, Chemical Abstracts, Embase, Index Copernicus, EBSCO, African Index Medicus, JournalSeek, Journal Citation Reports/Science Edition, Directory of Open Access Journals (DOAJ), African Journal Online, Bioline International, Open-J-Gate and Pharmacy Abstracts

\section{INTRODUCTION}

Heart failure results in progressive decreases in cardiac mechanical function. Cardiac failure involves multiple factors such as inflammation and neuro-hormonal changes, as well as lesions in cardiac, vascular smooth muscle, fibroblast and endothelial tissues [1]. Heart disease results in arrhythmias which are linked to disruption of $\mathrm{Ca}^{2+}$ homeostasis in cardiomyocytes [2]. Unfortunately, the treatment for heart failure with inhibitors of angiotensin converting enzyme and $\beta$-adrenergic blockers give only temporary relief from the associated symptoms. Heart failure patients are subjected to multiple medications that increase the risk of multiple drug interactions 
and toxicity [3]. Treatment responses vary, even in patients with similar clinical symptoms [4]. The latter may be due to variabilities in genetic information amongst individuals.

Heart failure results in morphological changes in myocardium due to metabolic and functional changes [5]. The cardiac tissue depends on fatty acid and glucose oxidation pathways for its energy needs. A condition of high fatty acid oxidation and less glucose oxidation results in 30 $\%$ reduction in cardiac efficiency [6]. Overall, this results in more lactate production and acidosis which alters tissue microenvironment and disturbs cellular homeostasis. Angiotensin II, the most well-known peptide hormone, affects cardio-myocytes by increasing the production of reactive oxygen species (ROS) which disrupt mitochondrial fatty acid oxidation, resulting in tissue damage [7-9].

The expression of different genes and their posttranslational modification varies as a function of the cardiac environment. These variations determine their cellular turnover. Thus, it is crucial to understand the regulation of these genes in different pathological stages [10]. Heart and neural crest derivatives expressed 1 (HAND1) is a cardiac transcription factor which shows elevated expression in heart failure [11]. Loss of HAND1 function results in morphogenic defects in the left ventricle [12]. Recent studies on CBS showed that its deficiency results in endothelial dysfunction [13]. It has also been reported that inhibition of CBS may be a therapeutic approach for ischemic injury [14]. Against this background, the actual roles of HAND1 and CBS expressions at different stages of obesity-induced cardiac stress were investigated in the present study.

\section{EXPERIMENTAL}

\section{Experimental animals}

Wild type mice with C57BL/6 background were used in this study. At 10 weeks of age, the mice are fed ad libitum on high fat diet (with $45 \%$ calories as fat, $35 \%$ carbohydrate and $20 \%$ calories as protein (Rodent Diet D12451, USA). The control mice were fed with standard diet containing $13 \%$ calories as fat, $67 \%$ carbohydrate and $20 \%$ calories as protein (2014S Rodent Maintenance Diet, Spain). The high fat and standard diets were fed for 7 months to group 1 mice (6 mice), and extended up to 12 months for group 2 mice (6 mice). Mice in the two groups were maintained in a laboratory set up at room temperature of $22 \pm 1^{\circ} \mathrm{C}$ and relative humidity of $55 \pm 5 \%$. The animal experiments were approved by the institutional ethical committee (approval no. XE2016331). The procedures and animal handling were conducted in agreement with National Guidelines of Animal Care Committee [15].

\section{Histology}

Dissected heart tissue was sliced into smaller sections and thoroughly washed with distilled water. They were then fixed in $10 \%$ formalin solution in a container for $48 \mathrm{~h}$ at $40{ }^{\circ} \mathrm{C}$. After fixation, the tissues were once again washed with water and transferred to $70 \%$ isopropyl alcohol solution for $45 \mathrm{~min}$. Thereafter, the tissues were processed by dehydration in increasing gradient concentration of isopropyl alcohol solution, and finally in absolute isopropyl alcohol. After complete dehydration process, the tissues were treated with xylene for $45 \mathrm{~min}$ to facilitate wax impregnation. They were then embedded in wax and made into blocks which were mounted on a microtome and sliced to obtain thin sections (5 $\mu \mathrm{m}$ in size). The processed sections were stained with hematoxylin \& eosin $(H$ \& $E)$ and visualized under the light microscope.

\section{Immunohistochemistry}

The paraffin-embedded heart tissues were subjected to thin sectioning ( $6 \mu \mathrm{m}$ size) using a microtome, and the sections were mounted on slides which were overlaid with water. The slides were placed in the oven at $60^{\circ} \mathrm{C}$ for $5 \mathrm{~min}$, to stretch out the sections. Then, the slides were washed with xylene, followed by isopropyl alcohol and finally rinsed in water. Antigen retrieval was carried out by boiling the slides in $10 \mathrm{mM}$ sodium citrate solution, $\mathrm{pH} 6.0$ for $15 \mathrm{~min}$. Then, the slides were treated with $4 \% \mathrm{H}_{2} \mathrm{O}_{2}$ solution for $20 \mathrm{~min}$. After washing, the slides were treated with blocking solution (4\% bovine serum albumin, BSA) in Tris-buffered saline, TBS containing $0.1 \%$ Tween 20) for $1 \mathrm{~h}$ at room temperature. Thereafter, the slides were incubated for $8 \mathrm{~h}$ at $4{ }^{\circ} \mathrm{C}$ with anti-HAND1 (Sigma-Aldrich, Hong Kong, China; catalogue no: HPA040925) or anti-CBS antibody (Abcam, Cambridge, MA, USA; catalogue number: ab96252) diluted in TBS containing $0.1 \%$ Tween 20. After incubation, the slides were washed thrice with phosphate buffer saline (PBS) and incubated with horse radish peroxidaseconjugated specific secondary antibody for $2 \mathrm{~h}$ at room temperature. After removing the secondary antibody by thorough washing using $1 \mathrm{X}$ PBS, the slides were incubated with 3,3'-diaminobenzidine (DAB) substrate for $5 \mathrm{~min}$ to enhance development of the specific signals. 


\section{Western blotting}

The dissected heart tissue was washed in icecold PBS solution and cut into smaller sections. Cell lysates were prepared from the tissue samples by homogenizing the tissue with $2 X$ protein sample in ice-cold condition to block protease activity. The prepared cell lysate was centrifuged at short spin to separate the supernatant which was transferred to a fresh tube and heated in a boiling water bath for $5 \mathrm{~min}$ to obtain the protein samples. The prepared protein samples were loaded onto SDS-PAGE gel in equal concentrations and run for $3 \mathrm{~h}$ at 50 V. The separated proteins in the gel were transferred to activated polyvinylidene difluoride (PVDF) membrane and blocked for $2 \mathrm{~h}$ with $4 \%$ BSA in TBST solution. Then, the membrane was incubated with the primary antibody anti-HAND1 (Sigma-Aldrich, Hong Kong, China; catalogue number: HPA040925) or anti-CBS antibody (Abcam, Cambridge, MA, USA catalogue number: ab96252) for $6 \mathrm{~h}$ at $4{ }^{\circ} \mathrm{C}$. After incubation, the membrane was washed and incubated with specific secondary antibody and finally developed with DAB kit to obtain the specific signals.

\section{Statistical analysis}

All experiments were performed in triplicate, and data are presented as mean \pm standard error of the mean (SEM). Significant differences between the groups were analyzed using Student's $t$-test. The statistical differences were considered significant at $p<0.05$. The experimental data were subjected to statistical analyses using version 22.0 SPSS software (SPSS Inc, Chicago, USA).

\section{RESULTS}

\section{Development of diet-induced mouse model of obesity and cardiac stress}

Obesity is one of the primary causes of heart disease. Indeed, obesity and diabetes are two major risk factors for heart disease [16]. Ingestion of a high fat diet for prolonged duration induces cardiac dysfunction and remodeling in experimental animals [17]. In the present study, C57BL/6 background male mice were fed high fat diet for two durations: 7 months and 12 months, as described in Materials and Methods section. Weight gain and loss of physical activity were observed in mice fed high fat diet for 7 consecutive months. With a mean weight of $62 \pm$ $3 \mathrm{~g}$, these mice gained 1.7 times more weight than the control mice (mean weight $=36 \pm 2 \mathrm{~g}$ ).
The mice fed high fat diet for 12 continuous months developed morbid obesity (mean weight $=132 \pm 5 \mathrm{~g}$ ), with thrice the weight gain of control mice of the same age (mean weight $=43 \pm 2 \mathrm{~g}$ ). These morbid obesity mice suffered from sleep apnea and breathing difficulties. These symptoms may be due to the accumulation of lipids in the heart, resulting in difficulty in pumping blood throughout the body, thereby affecting normal physiological functions.

\section{Histopathological changes in heart tissue}

Obesity burden for a continuous period of time induces cardiac remodeling which was evident in histological sections of heart tissue as obesity worsened (Figure $1 \mathrm{~A}-\mathrm{C}$ ). The basic structural appearance of the control heart tissue (12-month old mice) revealed that the myocardium fibers were arranged in a regular pattern with distinct nuclei and intercalated discs (Figure $1 \mathrm{~A}$ ). In contrast, the mice fed high fat diet for 7 continuous months developed cardiac tissue remodeling, with early degeneration of heart tissue (Figure 1B). The early changes became exacerbated in the mice fed the high fat diet for 12 continuous months, with clear evidence of tissue hardening (Figure 1C).
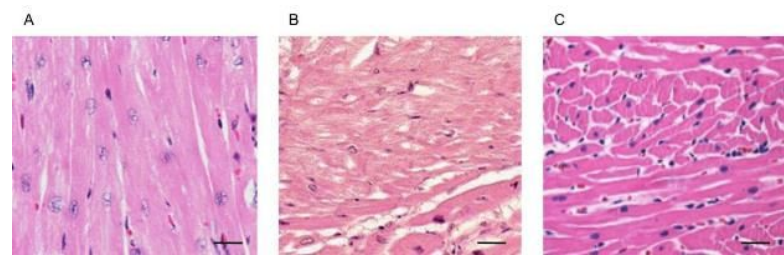

Figure 1: Re-modeling of heart tissue following obesity. A: Histological section of control heart tissue with distinct nucleus and cells separated by intercalated discs. B: Initial obesity-induced cardiac stress showing cardiac remodeling with tissue degeneration. C: Remodeling of cardiac tissue showing tissue hardening following critical obesity condition. Scale bar: $50 \mu \mathrm{m}$

\section{Critical role of HAND1 in maintenance of cardiac microarchitecture}

In the present study, there was limited expression of HAND1 in the control mice (7 month old mice), as shown in Figure $2 \mathrm{~A}$. However, on feeding the mice high fat diet for 7 continuous months, the expression of HAND1 was highly upregulated (Figure $2 \mathrm{~B}$ ), resulting in initiation of deleterious changes in cardiac microarchitecture. As the high fat diet feeding was continued for another 6 months, complete disorganization of cardiac tissue was observed, along with downregulation of expression of HAND1 (Figure $2 \mathrm{C}$ ). 

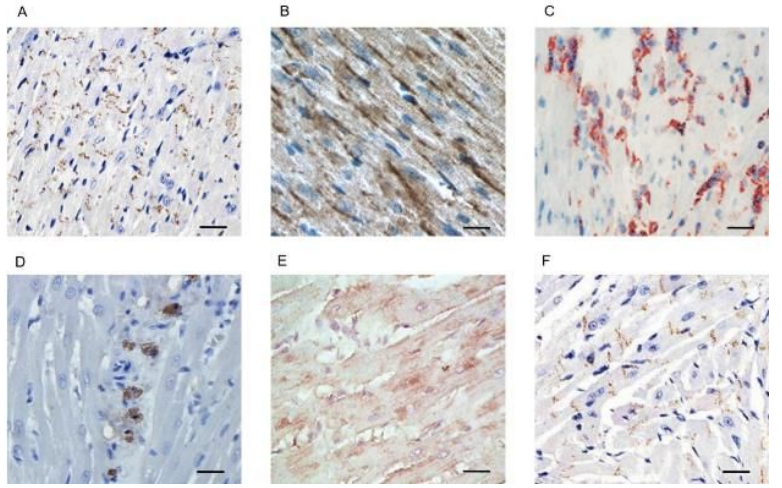

Figure 2: Expression patterns of HAND1 and CBS at different stages of obesity-induced heart stress. A Control heart tissue of 7-month-old mice with limited expression of HAND1. B: High fat diet-induced initial obesity stage showing upregulated expression of HAND1 in cardiac tissue. C: Intake of high fat diet for 12 months resulted in critical obesity and downregulated expression of HAND1 in cardiac tissue. D: Heart tissue from 7-month-old Control mice showing normal expression of CBS. E: Initial obesity mice showing upregulated expression of CBS in cardiac tissue. F: Heart tissue from critical stage obesity mice showing more cardiac remodeling, but low expression of CBS. Scale bar: $50 \mu \mathrm{m}$

\section{Overexpression of CBS altered cardiac microarchitecture}

There are disagreements in opinion on the effect of expression pattern of CBS on vascular health: some studies have indicated a protective role for CBS expression on vascular health $[13,18]$, while others ascribe a destructive role to it [14]. In the present study, the expression of CBS varied at different stages of obesity-induced stress in cardiac tissue (Figures $2 \mathrm{D}-\mathrm{F}$ ). In the control cardiac tissue (7-month-old mice), the expression of CBS was restricted to a specific location (Figure $2 \mathrm{D}$ ). However, due to stress induced by initial obesity $(7$ months of high fat diet exposure), the expression of CBS was markedly upregulated, resulting in initiation of destruction of cardiac cellular architecture (Figure $2 \mathrm{E}$ ). In the critical stage of obesity (due to 12 months of high fat diet intake), downregulated expression of CBS was observed (Figure $2 \mathrm{~F}$ ).

The quantitative expression of HAND1 and CBS were further cross-checked using western blotting (Figure 3 ). The results showed that the expression of HAND1 in initial obesity-induced cardiac was 4.3 times higher than that in control mice tissue, but the expression was downregulated in advanced stage obesity, with only 1.2-fold higher HAND1 expression than in control cardiac tissue. Similarly, CBS showed an upregulated expression pattern in initial obesityinduced cardiac tissue (3.7 times higher than control), but as the obesity reach critical stage, its expression was down to only 1.8 times higher than that in 7-month-old control mice. These results are shown in Figures 3 and 4.

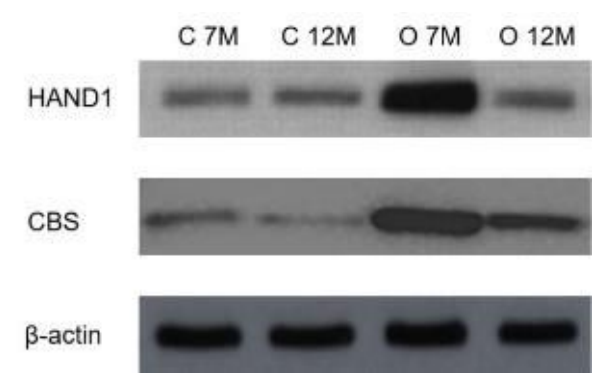

Figure 3: Western blotting analysis of HAND1 and CBS expressions. Lane 1 \& Lane 2 show optimum expressions of HAND1 and CBS in control heart tissue of 7-month- and 12-month-old mice. Lane 3 represents the upregulated expressions of HAND1 and CBS in cardiac tissue of mice fed high fat diet for 7 months. Lane 4 shows downregulated expressions of HAND1 and CBS in heart tissue of mice fed high fat diet for 12 months. (C: control mice; O $7 \mathrm{M}$ : obesity induced heart failure mice fed for 7 months; O 12M: obesity induced heart failure mice fed for 12 months).

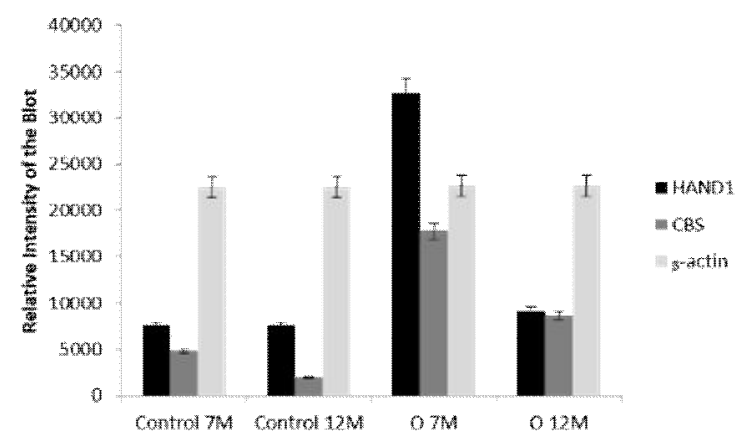

Figure 4: Quantification of HAND1 and CBS expressions in different stages of obesity-induced heart failure. Based on band intensity, the expressions of HAND1 and CBS in the two stages of obesityinduced heart failure were analysed and represented in bar diagram. The experiments were repeated more than three times to obtain concordant data presented as mean $\pm \mathrm{SD} ;{ }^{*} p<0.05$ was considered as statistically significant. ( $\mathrm{O} 7 \mathrm{M}=$ obesity-induced heart failure mice fed for 7 months; $\mathrm{O} 12 \mathrm{M}$ = obesityinduced heart failure mice fed for 12 months)

\section{DISCUSSION}

Obesity is a major health problem and a risk factor for stroke, diabetes, heart disease, hypertension, cancer and reproductive disorders. In prolonged obesity linked heart disease, cardiac remodeling occurs with aberrant expressions of many genes like Smad6 and TGF- $\beta$ [19]. Although the regulatory role of HAND1 and CBS are understood in general, not much was hitherto known about their roles in 
different pathological stages of obesity-induced cardiac failure.

An impressive corpus of evidence is available on obesity-induced cardiac remodeling [20]. In the present study, it was observed that C57BL/6 mice fed high fat diet for 7 months developed cardiac tissue remodeling and early degeneration of cardiac tissue. The continuous ingestion of high fat diet led to lethal obesity and cardiac tissue hardening due to deregulation of many genes, and production of inflammationassociated factors [21].

Studies have shown that HAND1 is involved in regulation of myocardial growth, proliferation and differentiation [22]. High expression of HAND1 has been reported in heart failure associated with arrhythmia [11]. The present study showed that at the initial stage of obesity-associated cardiac stress, HAND1 expression was upregulated, resulting in initiation of cardiac remodeling through tissue degeneration. However, following complete remodeling of cardiac tissue and tissue hardening, the HAND1 expression became downregulated. This implies an initial role for HAND1 in cardiac remodeling and heart failure. Studies have shown that HAND1 shows variable expression patterns, with high expression in developing heart, low expression in adulthood, and upregulated expression in adult heart failure [11]. The data from the present study suggest that at the extreme stage of heart failure, HAND1 expression is controlled, but at the initial stages of obesity-induced cardiac stress, its higher expression is involved in cardiac remodeling by activating many associated genes.

Impaired activity of CBS results in hyperhomocysteinemia, a risk factor for cardiovascular disease [23]. Similarly, it has been reported that upregulated expression of CBS occurs with increased production of $\mathrm{H}_{2} \mathrm{~S}$ which worsens ischemic injury [14]. The results obtained in the current study also support this mechanism i.e. the expressions of CBS and HAND1 in initial obesity are elevated, thereby exacerbating cardiac tissue stress and tissue hardening.

\section{CONCLUSION}

The results obtained in this study indicate that expressions of HAND1 and CBS are upregulated at the initial stage of obesity-induced cardiac stress, thereby worsening the disease condition. However, following cardiac tissue remodeling, their expressions are downregulated. Thus, HAND1 and CBS play essential roles in cardiac remodeling, and are promising therapeutic targets for obesity-induced cardiac injury.

\section{DECLARATIONS}

\section{Conflict of Interest}

No conflict of interest associated with this work.

\section{Contribution of Authors}

We declare that this work was done by the authors named in this article and all liabilities pertaining to claims relating to the content of this article will be borne by the authors. All the authors read the final version of the manuscript and approved it for publication. Xiandong Sun and Jian Cao contributed to this work equally. Xiandong Sun, Jian Cao and Ronghai Man conceived and designed the study. Xiandong Sun, Jian Cao, Haiming Tong, Xizhe Zhang, Yi Sun, Zhimin Wei collected and analyzed the data, while Ronghai Man wrote the manuscript.

\section{Open Access}

This is an Open Access article that uses a funding model which does not charge readers or their institutions for access and distributed under the terms of the Creative Commons Attribution License (http://creativecommons.org/licenses/by/ 4.0) and the Budapest Open Access Initiative (http://www.budapestopenaccessinitiative.org/rea d), which permit unrestricted use, distribution, and reproduction in any medium, provided the original work is properly credited.

\section{REFERENCES}

1. Aspromonte N, Gulizia MM, Clerico A, Di TG, Emdin M, Feola $M$, lacoviello $M$, Latini $R$, Mortara $A$, Valle $R$, et al. ANMCO/ELAS/SIBioC Consensus Document: biomarkers in heart failure. Eur Hear J Suppl 2017; 19(suppl_D): 102-112.

2. Bers DM. Altered cardiac myocyte $\mathrm{Ca}$ regulation in heart failure. Physiology 2006; 21(6): 380-387.

3. Flesch $M$, Erdmann E. The problem of polypharmacy in heart failure. Curr Cardiol Rep 2006; 8(3): 217-225.

4. Campen LC, Visser FC, Visser CA. Ejection fraction improvement by $\beta$-blocker treatment in patients with heart failure: an analysis of studies published in the literature. J Cardiovasc Pharmacol 1998; 32(suppl.1): 31-35.

5. Fragasso G. Deranged Cardiac Metabolism and the Pathogenesis of Heart Failure. Card Fail Rev 2016; 2(1): 8-13.

6. Lopaschuk GD, Ussher JR, Folmes CDL, Jaswal JS, Stanley WC. Myocardial fatty acid metabolism in health and disease. Physiol Rev 2010; 90(1): 207-258.

7. Dai DF, Johnson SC, Villarin JJ, Chin MT, Nieves-Cintrón M, Chen T, Marcinek DJ, Dorn GW, Kang YJ, Prolla TA,

Trop J Pharm Res, April 2019; 18(4): 751 
et al. Mitochondrial oxidative stress mediates angiotensin II-induced cardiac hypertrophy and Gaq overexpression-induced heart failure. Circ Res 2011; 108(7); 837-846.

8. Pellieux C, Aasum E, Larsen TS, Montessuit C, Papageorgiou I, Pedrazzini T, Lerch R. Overexpression of angiotensinogen in the myocardium induces downregulation of the fatty acid oxidation pathway. $J$ Mol Cell Cardiol 2006; 41(3): 459-466.

9. Pellieux C, Montessuit C, Papageorgiou I, Lerch R. Angiotensin II downregulates the fatty acid oxidation pathway in adult rat cardiomyocytes via release of tumour necrosis factor- $\alpha$. Cardiovasc Res 2009; 82(2): 341-350.

10. Agnetti G, Piepoli MF, Siniscalchi G, Nicolini F. New insights in the diagnosis and treatment of heart failure. Biomed Res Int 2015; 1199-1214.

11. Breckenridge RA, Zuberi Z, Gomes J, Orford R, Dupays L, Felkin LE, Clark JE, Magee Al, Ehler E, Birks EJ, et al. Overexpression of the transcription factor Hand1 causes predisposition towards arrhythmia in mice. J Mol Cell Cardiol 2009; 47(1): 133-141.

12. Vincentz JW, Toolan KP, Zhang W, Firulli $A B$. Hand factor ablation causes defective left ventricular chamber development and compromised adult cardiac function. PLoS Genet 2017;13(7):e1006922.

13. Saha S, Chakraborty PK, Xiong $X$, Dwivedi SK, Mustafi $S B$, Leigh NR, Ramchandran $R$, Mukherjee $P$, Bhattacharya $R$. Cystathionine $\beta$-synthase regulates endothelial function via protein S-sulfhydration. FASEB J 2016; 30(1): 441-456.

14. Chan SJ, Chai C, Lim TW, Yamamoto M, Lo EH, Lai MK, Wong PT. Cystathionine $\beta$-synthase inhibition is a potential therapeutic approach to treatment of ischemic injury. ASN Neuro 2015; 7(2): 1-14.
15. Garber JC (Chair). Committee for the Update of the Guide for the Care and Use of Laboratory Animals. Guide for the Care and Use of Laboratory Animals, eighth ed. Washington DC, USA: National Academy of Sciences; 2011.

16. Zhang PY. Cardiovascular disease in diabetes. Eur Rev Med Pharmacol Sci 2014; 18(15): 2205-2214.

17. Zeng H, Vaka VR, He X, Booz GW, Chen J. High-fat diet induces cardiac remodelling and dysfunction: assessment of the role played by SIRT3 loss. J Cell Mol Med 2015; 19(8): 1847-1856.

18. Risebro CA, Smart N, Dupays L, Breckenridge R, Mohun $T J$, Riley PR. Hand1 regulates cardiomyocyte proliferation versus differentiation in the developing heart. Development 2006; 133(22): 4595-4606.

19. Maclean KN, Greiner LS, Evans JR, Sood SK, Lhotak S, Markham NE, Stabler SP, Allen RH, Austin RC, Balasubramaniam $V$, et al. Cystathionine protects against endoplasmic reticulum stress-induced lipid accumulation, tissue injury, and apoptotic cell death. $J$ Biol Chem 2012; 287(38): 31994-32005.

20. Niu HM, Liu CL. The aberrant expression of Smad6 and TGF- $\beta$ in obesity linked cardiac disease. Eur Rev Med Pharmacol Sci 2017; 21(1): 138-142.

21. Pei H, Qu Y, Lu X, Yu Q, Lian K, Liu P, Yan W, Liu J, Ma $Y$, Liu $Y$, et al. Cardiac-derived adiponectin induced by long-term insulin treatment ameliorates myocardial ischemia/reperfusion injury in type 1 diabetic mice via AMPK signaling. Basic Res Cardiol 2013; 108(1): 322332.

22. Lundgren $\mathrm{CH}$, Brown SL, Nordt TK, Sobel BE, Fujii S. Elaboration of type-1 plasminogen activator inhibitor from adipocytes. Circulation 1996;93(1):106-110.

23. Collaboration HS. Homocysteine and risk of ischemic heart disease and stroke: a meta-analysis. Jama 2002; 288(16): 2015-2022. 